\title{
Measuring Green Innovation Efficiency for China's High-Tech Manufacturing Industry: A Network DEA Approach
}

\author{
Qunzhao Deng $\mathbb{D}^{\mathrm{D}},{ }^{1}$ Shuzhen Zhou $\mathbb{D}^{1},{ }^{1}$ and Feng Peng ${ }^{2}{ }^{2}$ \\ ${ }^{1}$ School of Management, Nanchang University, Nanchang 330031, China \\ ${ }^{2}$ School of Economics and Management, China Three Gorges University, Yichang 443002, China \\ Correspondence should be addressed to Shuzhen Zhou; zhoushuzhen@email.ncu.edu.cn and Feng Peng; pengfeng@ctgu.edu.cn
}

Received 31 May 2020; Accepted 27 July 2020; Published 17 August 2020

Academic Editor: Marcello Pellicciari

Copyright $(2020$ Qunzhao Deng et al. This is an open access article distributed under the Creative Commons Attribution License, which permits unrestricted use, distribution, and reproduction in any medium, provided the original work is properly cited.

Earlier studies on the innovation process in the high-tech manufacturing industry failed to take environmental pollution into account, making it difficult to estimate green innovation efficiency in the industry. From a perspective of innovation value chain, this paper decomposes green innovation process in the high-tech manufacturing industry into two stages: R\&D stage and achievement transformation stage; a network DEA approach considering undesirable outputs is utilized to estimate the green innovation efficiency in China's high-tech manufacturing industry. Compared with the method of conventional innovation efficiency without considering environmental pollution, the estimation method for green innovation efficiency can not only avoid bias of estimation results of provinces producing low pollution emissions like Inner Mongolia and Hainan but also reflect the volatility in efficiency of the high-tech manufacturing industry before and after the implementation of the environmental law.

\section{Introduction}

With increasing attention to the global competitiveness of the high-tech manufacturing industry since the 1990s, China has been steadily increasing its inputs in this area. A series of breakthroughs have been made in areas of manned space programs, the BeiDou Navigation Satellite System, and highspeed rail equipment. However, China's high-tech industries are still facing significant problems in terms of innovation capabilities and environmental pollution. Take Guangdong, a leading province in high-tech manufacturing, for example. According to statistics of the Development and Reform Commission of Guangdong Province, the province relies on importation for $90 \%$ of its key technologies and components, and $80 \%$ of the high-end CNC machines in the province are made in foreign countries. A large number of high-tech manufacturing firms without adequate innovative capabilities have been locked in low-value-adding, marginally profitable manufacturing processes, which has not only inhibited structural upgrade of the manufacturing industry and the improvement in the value chain but also caused a series of environmental pollution problems. In the meantime, China's high-tech manufacturing industry is also confronted with increasingly tightened constraints pertaining to resources and environment. In 2008, the State Environmental Protection Administration was upgraded to the Ministry of Environmental Protection. The Circular Economy Promotion Law of the People's Republic of China, which was officially implemented in January 2009, imposes more stringent controls over pollutant discharges from manufacturing firms. As such, with a severe scarcity of innovation resources and increasingly stringent environmental regulations, characterizing green innovation efficiency in the high-tech manufacturing industry is of a great significance for facilitating policy-making and sustainable development of industries in China.

Research literature focusing on innovation efficiency in China's high-tech manufacturing industry can be divided into three categories: the first category of literature deals with assessment of provincial innovation efficiency in the high-tech manufacturing industry with an emphasis on analyzing interprovincial differences in innovation efficiency 
[1-3]; another strand of literature has focused on industrylevel evaluations through examining industry-specific heterogeneity of innovation efficiency in the high-tech manufacturing industry [4-7]; finally, a small body of literature analyzed the influencing factors on innovation efficiency in the high-tech manufacturing industry based on survey data [8-11]. The most common method for estimating innovation efficiency in China's high-tech manufacturing industry is the DEA method [12-14], which has evolved from one-stage overall efficiency evaluation to multistage network efficiency evaluation [13-16].

Despite a large multitude of literature on innovation efficiency in China's high-tech manufacturing industry, few studies have estimated green innovation efficiency in the high-tech manufacturing industry while considering environmental factors $[17,18]$. A small fraction of literature did consider environmental pollution when estimating innovation efficiency in the high-tech manufacturing industry, but, in these studies, the overall innovation system was treated as a "black box" without further analyzing the internal structure of the innovation system [19-22]. Has there been any volatility in green innovation efficiency in China's high-tech manufacturing industry after the implementation of environmental regulations? What differences are there between the estimation results of green innovation efficiency with considering environmental pollution and those of conventional innovation efficiency without considering environmental pollution? These questions are still waiting to be answered $[23,24]$.

In this paper, a two-stage network DEA model with undesirable outputs is used to estimate green innovation efficiency of China's provincial high-tech manufacturing industry between 2006 and 2015; the volatility in green innovation efficiency in the high-tech manufacturing industry before and after the implementation of the Circular Economy Promotion Law of the People's Republic of China is examined, confirming that the method for estimating innovation efficiency without considering environmental pollution can result in bias. This paper is divided into six sections. The first section is the introduction. In the second section, a framework for the concept of green innovation in the high-tech manufacturing industry is established from the perspective of innovation value chain. The third section outlines the estimation method, indicators, and data employed in this paper. In the fourth section, the network DEA method considering environmental pollution is employed to estimate green innovation efficiency in China's high-tech manufacturing industry, and estimation results of conventional innovation efficiency without considering environmental pollution are also provided. The fifth section presents a discussion of research results, including the significance and limitations of the research, as well as a direction for future research. The sixth section provides the conclusion and implications.

\section{Green Innovation Process in the High-Tech Manufacturing Industry}

To carry out innovation activities, an organization must first acquire relevant knowledge, convert it into new products and processes, and then achieve added value through these innovation outputs. For such a circular process from knowledge acquisition, conversion to utilization constitutes an innovation value chain (IVC) $[25,26]$. The IVC represents a comprehensive analytical framework that decomposes innovation into multiple stages in order to specify its operating processes. Using IVC, managers are able to identify organizational weaknesses and select suitable innovation tools and approaches $[25,27]$. Based on IVC, the innovation process of an industry can be divided into two stages: the R\&D stage and the achievement transformation stage [28]. In the first stage, universities, research institutions, and firms put in technological resources and convert them into patent achievements through research and development; firms further transform some of the patents generated in the first stage into economic and societal benefits in the second stage, during which the inputs usually include other factors like capital and labor [28, 29]. Drawing on studies on the two-stage innovation process of China's high-tech manufacturing industry [29] and considering the factor of environmental pollution in the innovation process [30], this paper proposes the conceptual framework of green innovation in the high-tech manufacturing industry from the IVC perspective (see Figure 1).

Based on the IVC perspective, green innovation efficiency in the high-tech manufacturing industry can be decomposed into the R\&D efficiency in the first stage and the achievement transformation efficiency in the second stage. The former reflects the level to which scientific and technological resources are converted into technological achievements by research actors, which is measured by the ratio of the output to the input of $\mathrm{R} \& \mathrm{D}$; meanwhile the latter reflects the capability of firms to transform technological achievements into economic outputs and environmental benefits, which is measured by the ratio of the output to the input of achievement transformation [17, 31]. Drawing references from existing studies on the input and output indicators pertaining to the two-stage green innovation efficiency in the high-tech manufacturing industry $[28,29]$ and considering the availability of data, this paper considers $R \& D$ capital and $R \& D$ personnel as inputs of the $R \& D$ stage [9], and the number of patent applications and the number of invention patents are owned as intermediate outputs (the outputs in the R\&D stage are also the inputs in the achievement transformation stage) [23]; capital and labor are selected as the supplementary inputs in the achievement transformation stage $[29,32]$; and new product sales revenue, prime operating revenue, and pollutant emissions are used as the final outputs $[30,33,34]$. 


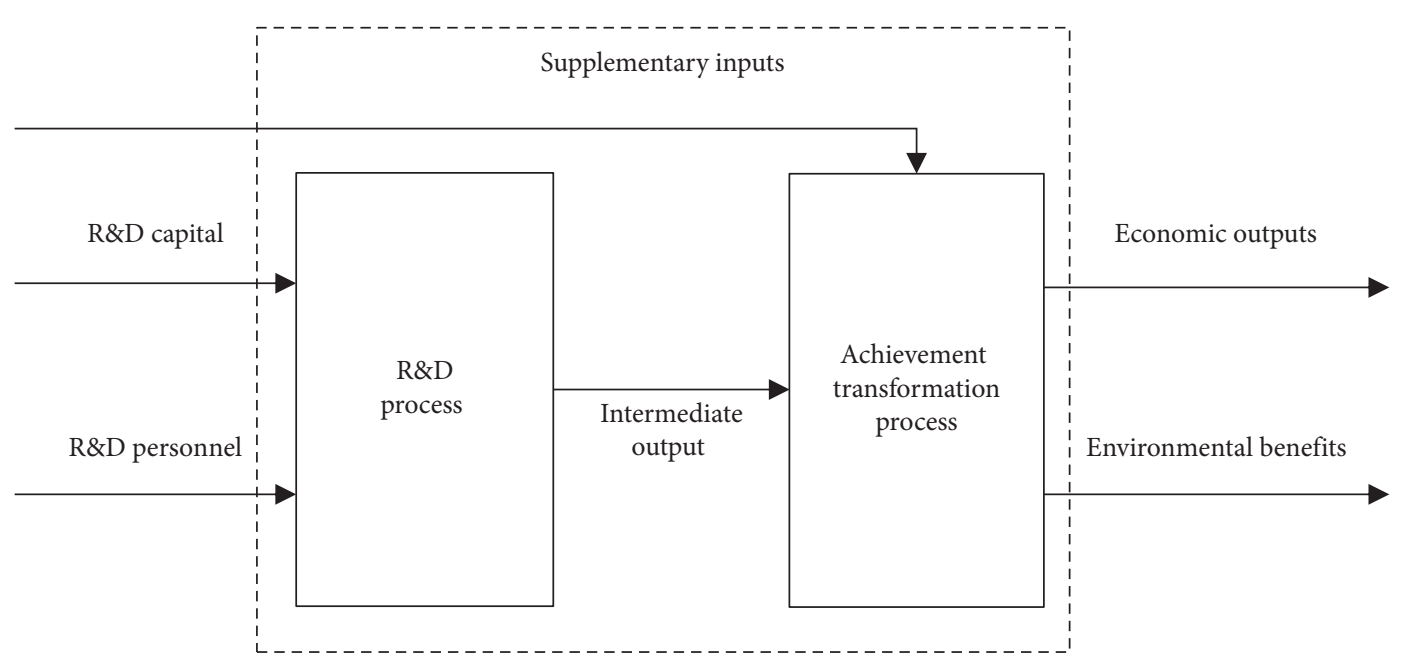

Figure 1: Conceptual framework of green innovation in the high-tech manufacturing industry.

\section{Materials and Methods}

3.1. A Two-Stage Network DEA Model with Undesirable Outputs. The innovation process in the high-tech manufacturing industry entails multiple inputs and outputs. Data envelopment analysis (DEA) is highly applicable to estimate the efficiency of such a process [35, 36]. When estimating innovation efficiency in the high-tech manufacturing industry, the conventional DEA method views innovation as a "black box," failing to consider its internal operations. The network DEA approach emerging in recent years is able to accurately portray the operating process of decision-making units (DMUs) and provide well-targeted improvement solutions [37-40]. Due to the fact that green innovation process in the high-tech manufacturing industry is divided into two stages under the IVC perspective, there is a necessity to use the network DEA model to estimate the green innovation efficiency [30,41]. When assessing innovation efficiency, the conventional network DEA approach either fails to consider undesirable outputs or fails to utilize the weak disposability assumption when addressing undesirable outputs [42, 43]. Maghbouli et al. [44] assumed variable returns to scale and the weak disposability of undesirable outputs, proposing a two-stage network DEA model with undesirable outputs which has a considerably high applicability to estimate the green innovation efficiency in China's high-tech manufacturing industry.

Assume that there are K DMUs and each DMU consists of two stages. In the first stage, the initial inputs into the $k$-th $\mathrm{DMU}_{k}$ are $x_{k}=\left(x_{1 k}, \ldots, x_{\mathrm{Nk}}\right)$, and the desirable intermediate outputs are $v_{k}=\left(v_{1 k}, \ldots, v_{\mathrm{Mk}}\right)$. In the second stage, the inputs are twofold: first, the desirable intermediate outputs in the first stage $v_{k}=\left(v_{1 k}, \ldots, v_{\mathrm{Mk}}\right)$ and the external inputs $z_{k}=\left(z_{1 k}, \ldots, z_{\mathrm{Tk}}\right)$, the desirable and undesirable outputs of which are $y_{k}=\left(y_{1 k}, \ldots, y_{\mathrm{Sk}}\right)$ and $w_{k}=\left(w_{1 k}, \ldots, w_{\mathrm{Jk}}\right)$, respectively. The DMU pending to be evaluated is $\mathrm{DMU}_{0}$; under the assumptions of variable returns to scale and weak disposability, the global efficiency of the two-stage network DEA with undesirable final outputs can be solved using the following model [44]:
$\operatorname{Min} e_{0}=\frac{1}{2}\left[\frac{1}{N+J}\left(\sum_{n=1}^{N} \beta_{N}+\sum_{j=1}^{J} \theta_{j}\right)+\frac{1}{T}\left(\sum_{t=1}^{T} \varphi_{t}\right)\right]$

s.t.

Stage 1 constraints:

$\sum_{k=1}^{K}\left(\alpha^{k}+\mu^{k}\right) x_{n}^{k} \leq \beta_{n} x_{n}^{0}, \quad n=1, \ldots, N$,

$\sum_{k=1}^{K} \alpha^{k} v_{m}^{k} \geq v_{m}^{0}, \quad m=1, \ldots, M$

$\sum_{k=1}^{K} \alpha^{k} w_{j}^{k}=\theta_{j} w_{j}^{0}, \quad j=1, \ldots, J$,

Stage 2 constraints:

$\sum_{k=1}^{K} \alpha^{k} v_{m}^{k} \geq v_{m}^{0}, \quad m=1, \ldots, M$

$\sum_{k=1}^{K}\left(\alpha^{k}+\mu^{k}\right) z_{t}^{k} \leq \varphi_{t} z_{t}^{0}, \quad t=1, \ldots, T$

$\sum_{k=1}^{K}\left(\alpha^{k}+\mu^{k}\right) y_{r}^{k} \geq y_{r}^{0}, \quad r=1, \ldots, S$,

generic constraints:

$\sum_{k=1}^{K}\left(\alpha^{k}+\mu^{k}\right)=1$,

$\alpha^{k}, \mu^{k} \geq 0, \quad k=1, \ldots, K$,

$0 \leq \theta_{j}, \beta_{n}, \varphi_{t} \leq 1 \quad$ for all $j, n, t$. 
In the object function, $(1 / N+J)\left(\sum_{n=1}^{N} \beta_{N}+\sum_{j=1}^{J} \theta_{j}\right)$ is Russell's measure of the R\&D efficiency in the first stage, $(1 / T)\left(\sum_{t=1}^{T} \varphi_{t}\right)$ is Russell's measure of the achievement transformation efficiency in the second stage.

3.2. Indicators and Data. Under the IVC perspective, green innovation in the high-tech manufacturing industry can be divided into two stages: R\&D stage and achievement transformation stage. Inputs in the $R \& D$ stage include $R \& D$ capital and R\&D personnel. R\&D personnel is measured by the full-time equivalents of $R \& D$ personnel (FTERDP), while $R \& D$ capital is measured by the $R \& D$ capital stock (RDS) $[9,30]$. The outputs from the $R \& D$ stage are the number of patent applications (PA) and the number of patents owned (NP) [23]. The supplementary inputs in the achievement transformation stage are physical capital and labor; the former is measured by physical capital stock $(K)$, while the latter is measured by the number of employees in the high-tech manufacturing industry $(L)[29,32]$. The desirable outputs in the achievement transformation stage are new product sales revenue (YNP) and prime operating revenue $(Y)$ [30]. The undesirable outputs of the achievement transformation stage are pollutant emissions. Considering the fact that $\mathrm{SO}_{2}$ as one of the major environmental pollutants has a considerably high homogeneity, $\mathrm{SO}_{2}$ emission is selected as the indicator of undesirable outputs [34].

Data on full-time equivalents (FTERDP), number of patent applications (PA), number of patents owned (NP), number of employees $(L)$, new product sales revenue (YNP), and prime operating revenue $(Y)$ are obtained from China Statistics Yearbook on High Technology Industry. The data used to estimate R\&D capital stock (RDS) and physical capital stock $(K)$ are also from China Statistics Yearbook on High Technology Industry. Data on $\mathrm{SO}_{2}$ emission $\left(\mathrm{BSO}_{2}\right)$ are obtained from China Statistical Yearbook on Environment, and the method used to calculate $\mathrm{SO}_{2}$ emissions in China's provincial high-tech manufacturing industry is derived from Peng and Zhou [45].

Statistical data of 28 provinces in mainland China (data of other provinces are missing) spanning from 2006 to 2015 were selected to measure the green innovation efficiency in the high-tech manufacturing industry (see Table 1).

\section{Results}

4.1. Measurement of Green Innovation Efficiency. Based on the panel data of Chinese provinces spanning from 2006 to 2015 , equation (1) was used to calculate the green innovation efficiency of China's provincial high-tech manufacturing industry, the results of which are shown in Table 2.

As can be known from Table 2, when measuring the green innovation efficiency in China's provincial high-tech manufacturing industry from the IVC perspective, the green innovations of 4 provinces, namely, Beijing, Guangdong, Inner Mongolia, and Hainan, are effective, all of which are 1.000 , while those of other provinces are ineffective. Among the ineffective provinces, Jiangsu, Ningxia, Shanghai, and
Tianjin have relatively higher green innovation efficiencies in their high-tech manufacturing industry, with annual mean values between 2006 and 2015 being 0.949, 0.877, 0.866 , and 0.839 , respectively. The province having the lowest green innovation efficiency in its high-tech manufacturing industry is Shaanxi, with an annual mean value between 2006 and 2015 being only 0.181 . Heilongjiang, Guizhou, Hubei, and Anhui also showed relatively lower green innovation efficiencies in their high-tech manufacturing industry, with annual mean values being $0.269,0.276,0.332$, and 0.333 , respectively. As such, the green innovation efficiency varies significantly across China's provincial high-tech manufacturing industries, with the majority of provinces having a relatively low green innovation efficiency.

Based on China Statistics Yearbook on High Technology Industry, these provinces are divided into three regions, namely, the eastern, central, and western regions. Regional differences in green innovation efficiency in China's hightech manufacturing industry are shown in Figure 2.

As can be seen, between 2006 and 2015, the eastern region has an annual mean value in terms of green innovation efficiency in the high-tech manufacturing industry higher than those of the central and western regions. The year 2009 represents a "turning point" whereby green innovation efficiencies of the eastern and western regions in their high-tech manufacturing industry shift from growth to decline. Green innovation efficiency in the high-tech manufacturing industry exhibited a declining trend between 2009 and 2014 in the eastern region, while it showed a climbing trend between 2010 and 2015 in the western region. For the central region, green innovation efficiency in the high-tech manufacturing industry came to its first "turning point," shifting from growth to decline, in 2008; then it exhibited a continuous drop for two years in a row from 2009 to 2010 , followed by an $S$-shaped growth after 2010. In general, green innovation efficiency in China's high-tech manufacturing industry showed a rapid growth from 2006 to 2009, arriving at a "turning point" in 2009 and then exhibiting a slow growing trend between 2010 and 2015.

On the one hand, green innovation efficiency in China's high-tech manufacturing industry shows considerable provincial differences, with the majority of provinces having a relatively low efficiency, which explains the relatively low mean value of green innovation efficiency in the high-tech manufacturing industry. On the other hand, green innovation efficiencies in the high-tech manufacturing industry across the eastern, central, and western regions experienced major volatilities between 2006 and 2015, but the three regions exhibited significantly different variation trends in terms of their green innovation efficiencies.

Based on the IVC perspective, this paper decomposes green innovation efficiency into R\&D efficiency and achievement transformation efficiency for further analysis.

As can be known from Table 2, when taking environmental pollution into consideration, only Beijing, Guangdong, Inner Mongolia, and Hainan are effective in the R\&D stage in their high-tech manufacturing industries, with efficiencies being invariably 1.000 between 2006 and 2015; 
TABLE 1: Descriptive statistical results of input-output variables for researched provinces in total.

\begin{tabular}{|c|c|c|c|c|c|}
\hline Variable & Unit & Mean & Std. dev. & Min & Max \\
\hline R\&D capital stock (RDS ) & 100 million yuan & 106.535 & 231.823 & 0.178 & 2044.384 \\
\hline Full-time equivalents (FTERDP) & Man-year & 16932.630 & 33175.270 & 11.800 & 224334.000 \\
\hline Number of patent applications (PA) & Piece & 3307.543 & 7647.005 & 1.000 & 58119.000 \\
\hline Number of patents owned (NP) & Piece & 3196.386 & 11378.510 & 1.000 & 125471.000 \\
\hline Physical capital stock $(K)$ & 100 million yuan & 988.718 & 1219.791 & 22.949 & 9514.534 \\
\hline Number of employees $(L)$ & Person & 391334.700 & 713679.400 & 4739.000 & 3890108.000 \\
\hline New product sales revenue (YNP) & 100 million yuan & 695.091 & 1544.006 & 0.019 & 12396.770 \\
\hline Prime operating revenue $(Y)$ & 100 million yuan & 2668.986 & 5048.211 & 11.033 & 33491.550 \\
\hline $\mathrm{SO}_{2}$ emission $\left(\mathrm{BSO}_{2}\right)$ & 10,000 tons & 3708.555 & 3129.999 & 381.206 & 15379.350 \\
\hline
\end{tabular}

TABLE 2: Green innovation efficiency and its decompositions from 2006 to 2015.

\begin{tabular}{|c|c|c|c|}
\hline Area & Green innovation efficiency & R\&D efficiency & Achievement transformation efficiency \\
\hline Beijing & 1.000 & 1.000 & 1.000 \\
\hline Tianjin & 0.839 & 0.699 & 0.979 \\
\hline Hebei & 0.443 & 0.286 & 0.600 \\
\hline Shanxi & 0.412 & 0.465 & 0.359 \\
\hline Inner Mongolia & 1.000 & 1.000 & 1.000 \\
\hline Liaoning & 0.399 & 0.297 & 0.502 \\
\hline Jilin & 0.677 & 0.550 & 0.804 \\
\hline Heilongjiang & 0.269 & 0.129 & 0.409 \\
\hline Shanghai & 0.866 & 0.732 & 1.000 \\
\hline Jiangsu & 0.949 & 0.897 & 1.000 \\
\hline Zhejiang & 0.511 & 0.346 & 0.677 \\
\hline Anhui & 0.333 & 0.266 & 0.400 \\
\hline Fujian & 0.662 & 0.489 & 0.835 \\
\hline Jiangxi & 0.365 & 0.270 & 0.460 \\
\hline Shandong & 0.589 & 0.479 & 0.699 \\
\hline Henan & 0.635 & 0.493 & 0.776 \\
\hline Hubei & 0.332 & 0.216 & 0.448 \\
\hline Hunan & 0.457 & 0.408 & 0.506 \\
\hline Guangdong & 1.000 & 1.000 & 1.000 \\
\hline Guangxi & 0.519 & 0.414 & 0.623 \\
\hline Hainan & 1.000 & 1.000 & 1.000 \\
\hline Chongqing & 0.635 & 0.547 & 0.723 \\
\hline Sichuan & 0.462 & 0.429 & 0.495 \\
\hline Guizhou & 0.276 & 0.159 & 0.392 \\
\hline Yunnan & 0.536 & 0.476 & 0.597 \\
\hline Shaanxi & 0.181 & 0.095 & 0.266 \\
\hline Gansu & 0.569 & 0.499 & 0.640 \\
\hline Ningxia & 0.877 & 0.753 & 1.000 \\
\hline Eastern region & 0.751 & 0.657 & 0.845 \\
\hline Middle region & 0.435 & 0.350 & 0.520 \\
\hline Western region & 0.562 & 0.486 & 0.637 \\
\hline Overall & 0.600 & 0.514 & 0.685 \\
\hline
\end{tabular}

The eastern region includes Beijing, Tianjin, Hebei, Liaoning, Shanghai, Jiangsu, Zhejiang, Fujian, Shandong, Guangdong, and Hainan; the middle region includes Shanxi, Jilin, Heilongjiang, Anhui, Jiangxi, Henan, Hubei, and Hunan; the western region includes Guangxi, Inner Mongolia, Chongqing, Sichuan, Guizhou, Yunnan, Shaanxi, Gansu, and Ningxia. Other provinces were not included in the sample due to serious data missing.

meanwhile the other 24 provinces are ineffective. Among the ineffective provinces, Jiangsu, Ningxia, and Shanghai showed relatively higher R\&D efficiencies in their high-tech manufacturing industries, with annual mean values being 0.897, 0.753, and 0.732, respectively between 2006 and 2015 . In some provinces, the $\mathrm{R} \& \mathrm{D}$ efficiency in the high-tech manufacturing industry varies significantly across different periods. For example, Ningxia had R\&D efficiency lower than 0.500 between 2006 and 2008, but it reached 1.000 between 2011 and 2015. From 2006 to 2015, the province having the lowest $R \& D$ efficiency in its high-tech manufacturing industry is Shaanxi, with an annual mean value of only 0.095. In addition, Heilongjiang, Guizhou, Hubei, Anhui, Jiangxi, Hebei, and Liaoning also have an annual mean value lower than 0.300 in their R\&D efficiencies. Figure 3 shows the regional differences in terms of R\&D efficiency in China's high-tech manufacturing industry while considering environmental pollution.

When taking environmental pollution into consideration, the annual mean value of R\&D efficiency in the high- 


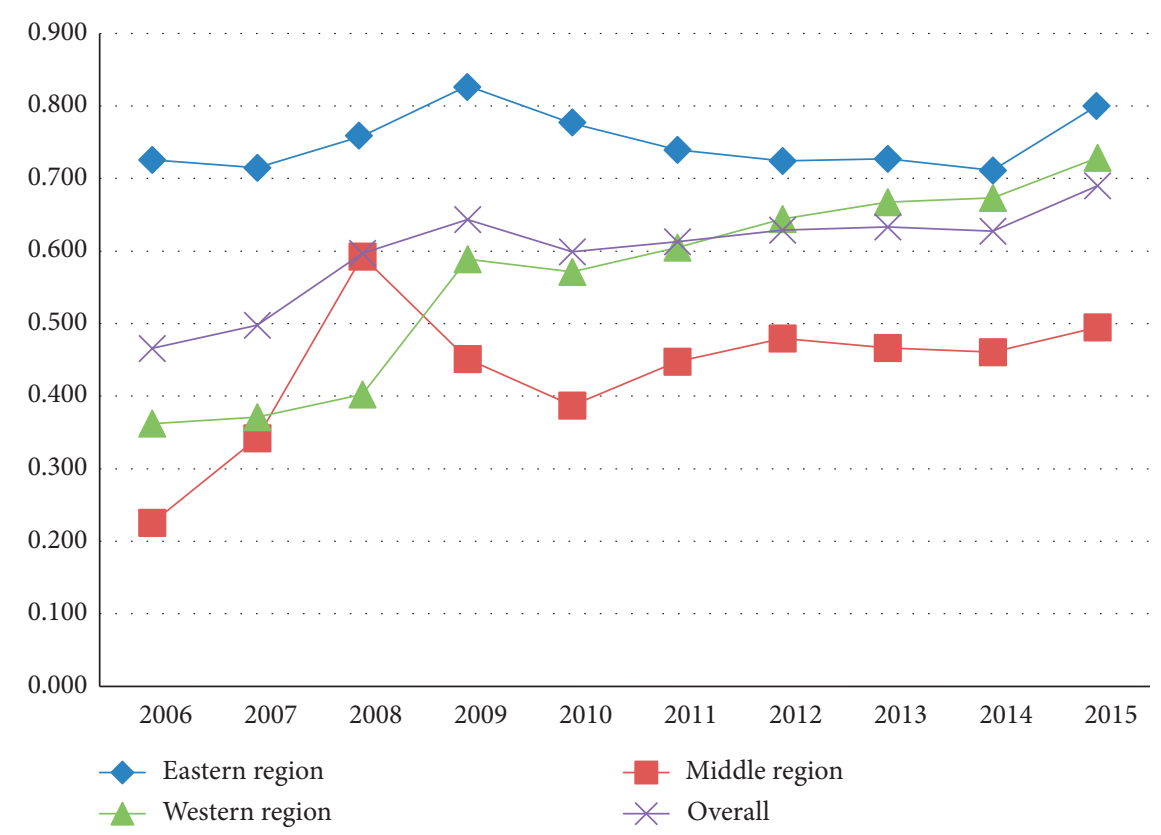

FIGURE 2: Regional differences in green innovation efficiency in China's high-tech manufacturing industry.

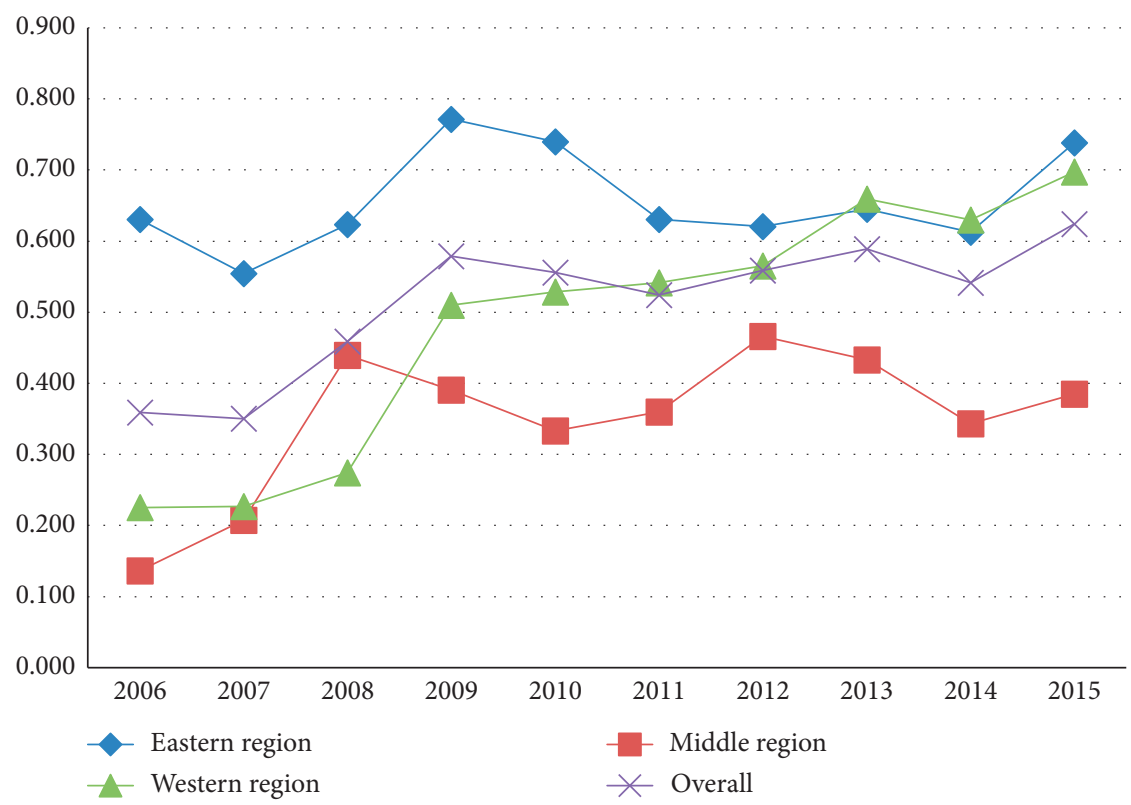

FIGURE 3: Regional differences in R\&D efficiency in China's high-tech manufacturing industry while considering environmental pollution.

tech manufacturing industry in the eastern region was higher than those in the central and western regions between 2006 and 2015, while the annual mean value of the central region is lower than that of the western region. In general, the annual mean value of R\&D efficiency in China's hightech manufacturing industry is only 0.514. The year 2009 represents a "turning point" for eastern region's R\&D efficiency in the high-tech manufacturing industry, shifting from growth to decline. From 2009 to 2015, R\&D efficiency in the high-tech manufacturing industry in the eastern region fluctuated in the range of $[0.600,0.800]$. In the central region, R\&D efficiency in the high-tech manufacturing industry experienced a rapid growth between 2006 and 2008, followed by a continuous drop for two consecutive years from 2009 to 2010, and then fluctuated in the range of [0.300, 0.500] from 2011 to 2015. In the western region, R\&D efficiency in the high-tech manufacturing industry exhibited a climbing trend from 2006 to 2015, with a minor volatility only in 2014. In overall, when taking environmental pollution into consideration, R\&D efficiency in China's hightech manufacturing industry exhibited an "S"-shaped growing trend from 2006 to 2015. 
As can be known from Table 2, when taking environmental pollution into consideration, there are 7 effective provinces in the achievement transformation stage in their high-tech manufacturing industries, which are Beijing, Inner Mongolia, Shanghai, Jiangsu, Guangdong, Hainan, and Ningxia; other provinces, in comparison, are ineffective. Among the ineffective provinces, Tianjin, Fujian, and Jilin have relatively higher achievement transformation efficiencies, with annual mean values being $0.979,0.835$, and 0.804 , respectively. The province having the lowest achievement transformation efficiency in the high-tech manufacturing industry is Shaanxi, which has an annual mean value of only 0.266 . In addition, Shanxi and Guizhou also showed relatively low achievement transformation efficiencies in their high-tech manufacturing industry, with annual mean values being 0.359 and 0.392 , respectively. Figure 4 displays the regional differences in terms of achievement transformation efficiency in China's high-tech manufacturing industry while considering environmental pollution.

When taking environmental pollution into consideration, the achievement transformation efficiency in the hightech manufacturing industry in the eastern region between 2006 and 2015 was significantly higher than those of the central and western regions. However, the eastern region's achievement transformation efficiency in the high-tech manufacturing industry constantly fluctuated within the range of $[0.800,0.900]$. In the central region, achievement transformation efficiency in the high-tech manufacturing industry peaked at 0.746 in 2008 and then exhibited a declining trend for two consecutive years from 2009 and 2010, followed by an " $S$ "-shaped growing trend between 2010 and 2015. In the western region, achievement transformation efficiency in the high-tech manufacturing industry exhibited an "S"-shaped growing trend from 2006 to 2015, with a downward volatility only in 2010 and in 2013. Generally, while considering environmental pollution, achievement transformation efficiency in China's high-tech manufacturing industry exhibited an upward trend from 2006 to 2015 and then showed an inverted " $U$ "-shaped change between 2006 and 2010, followed by an "S"-shaped growing trend from 2011 to 2015.

\subsection{Measurement of Conventional Innovation Efficiency.} To analyze the differences between the green innovation efficiency and conventional innovation efficiency estimation results, equation (1) is utilized to calculate the conventional innovation efficiency of China's provincial high-tech manufacturing industry without considering environmental pollution, as shown in Table 3.

As can be known from Table 3, when conventional innovation efficiency in China's provincial high-tech manufacturing industry is estimated from the IVC perspective, Beijing and Guangdong are found to be effective, while other provinces are ineffective. Among the ineffective provinces, Inner Mongolia, Jiangsu, Hainan, and Shanghai showed relatively higher conventional innovation efficiencies in their high-tech manufacturing industries, with annual mean values being $0.987,0.958,0.945$, and 0.915 , respectively. The province having the lowest conventional innovation efficiency in high-tech manufacturing industry is Shaanxi, with an annual mean value of only 0.182 . In addition, Heilongjiang and Hebei also showed relatively low conventional innovation efficiencies in their high-tech manufacturing industries, the annual mean values of which are 0.208 and 0.276 , respectively. Figure 5 shows the regional differences in terms of conventional innovation efficiency in China's high-tech manufacturing industry without considering environmental pollution.

From a regional perspective, the eastern region has a conventional innovation efficiency in the high-tech manufacturing industry higher than those of the central and western regions and higher than the nationwide average level. However, conventional innovation efficiency of the eastern region constantly fluctuates within the range of [0.697, 0.769]. From 2006 to 2015, the central region's conventional innovation efficiency in the high-tech manufacturing industry was constantly lower than those of the western region and nationwide average; in the meantime, both the central and western regions exhibited a growing trend in terms of their conventional innovation efficiency in the high-tech manufacturing industry. In general, conventional innovation efficiency in China's high-tech manufacturing industry exhibits a growing trend.

The conventional innovation efficiency is further decomposed into R\&D efficiency and achievement transformation efficiency from the IVC perspective.

As can be known from Table 3, when not taking environmental pollution into account, only Beijing and Guangdong are effective in the R\&D stage in their high-tech manufacturing industries, while other provinces are ineffective. Among the ineffective provinces, Inner Mongolia, Hainan, Jiangsu, and Shanghai have a relatively higher R\&D efficiency in their high-tech manufacturing industries, with annual mean values being $0.979,0.922,0.915$, and 0.830 , respectively. The province having the lowest $\mathrm{R} \& \mathrm{D}$ efficiency in China's high-tech manufacturing industry is Shaanxi, which has an annual mean value of only 0.095. In addition, Heilongjiang, Guizhou, Hebei, Hubei, Anhui, Jiangxi, Zhejiang, and Liaoning also showed relatively lower R\&D efficiencies in their high-tech manufacturing industries, with annual mean values being invariably lower than 0.300 . Figure 6 presents the regional differences in terms of R\&D efficiency in China's high-tech manufacturing industry without considering environmental pollution.

When not taking environmental pollution into account, the eastern region has R\&D efficiency in its high-tech manufacturing industry higher than those of the central and western regions. The eastern region's R\&D efficiency in the high-tech manufacturing industry grew rapidly between 2007 and 2010 and then exhibited an "S"-shaped volatility from 2011 to 2015, without showing a significantly growing trend. In the central region, R\&D efficiency in the high-tech manufacturing industry gained a rapid growth between 2007 and 2010, followed by an "S"-shaped growth from 2011 to 2015. In the western region, $R \& D$ efficiency in the high-tech manufacturing industry achieved a rapid growth from 2006 


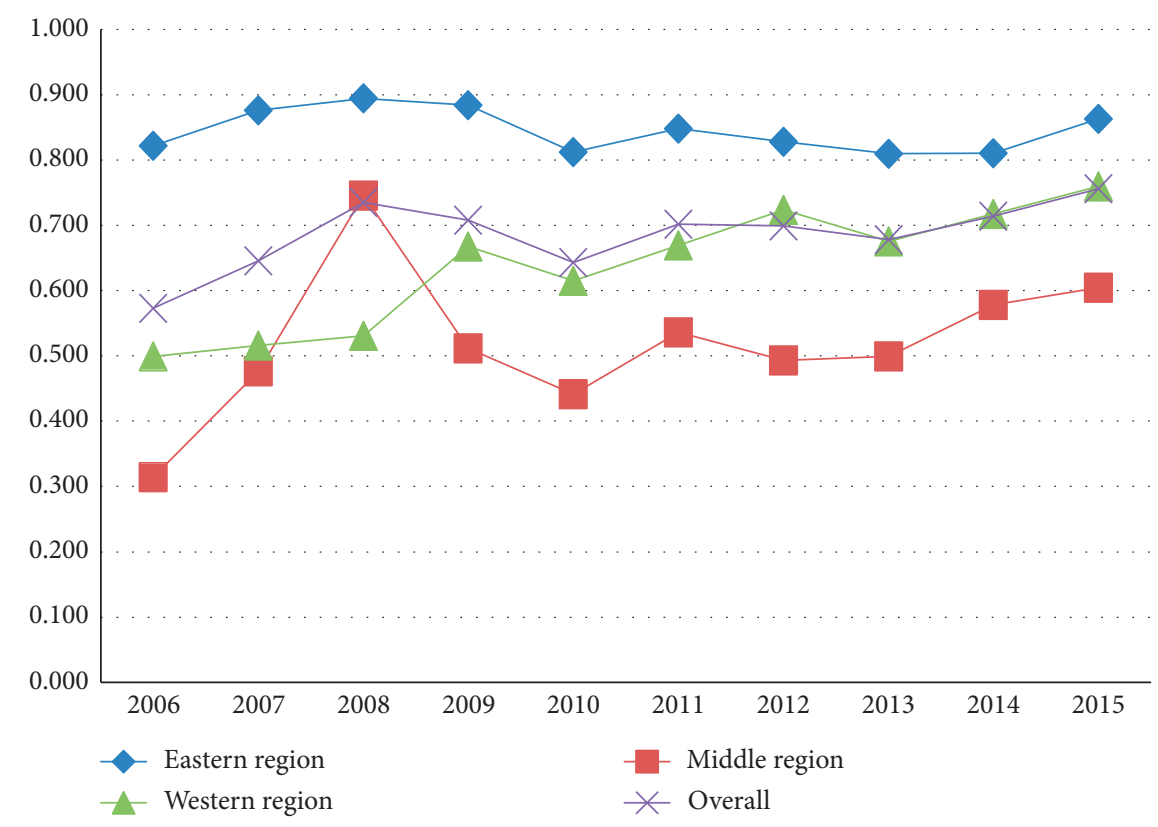

Figure 4: Regional differences in achievement transformation efficiency in China's high-tech manufacturing industry while considering environmental pollution.

TABLE 3: Conventional innovation efficiency and its decompositions from 2006 to 2015.

\begin{tabular}{|c|c|c|c|}
\hline Area & Conventional innovation efficiency & R\&D efficiency & Achievement transformation efficiency \\
\hline Beijing & 1.000 & 1.000 & 1.000 \\
\hline Tianjin & 0.870 & 0.748 & 0.991 \\
\hline Hebei & 0.276 & 0.200 & 0.351 \\
\hline Shanxi & 0.444 & 0.608 & 0.280 \\
\hline Inner Mongolia & 0.987 & 0.979 & 0.995 \\
\hline Liaoning & 0.390 & 0.287 & 0.493 \\
\hline Jilin & 0.515 & 0.452 & 0.578 \\
\hline Heilongjiang & 0.208 & 0.114 & 0.301 \\
\hline Shanghai & 0.915 & 0.830 & 1.000 \\
\hline Jiangsu & 0.958 & 0.915 & 1.000 \\
\hline Zhejiang & 0.507 & 0.244 & 0.770 \\
\hline Anhui & 0.336 & 0.232 & 0.440 \\
\hline Fujian & 0.695 & 0.489 & 0.900 \\
\hline Jiangxi & 0.284 & 0.233 & 0.334 \\
\hline Shandong & 0.607 & 0.489 & 0.726 \\
\hline Henan & 0.411 & 0.412 & 0.409 \\
\hline Hubei & 0.311 & 0.203 & 0.419 \\
\hline Hunan & 0.356 & 0.304 & 0.408 \\
\hline Guangdong & 1.000 & 1.000 & 1.000 \\
\hline Guangxi & 0.479 & 0.541 & 0.416 \\
\hline Hainan & 0.945 & 0.922 & 0.969 \\
\hline Chongqing & 0.605 & 0.517 & 0.694 \\
\hline Sichuan & 0.415 & 0.375 & 0.456 \\
\hline Guizhou & 0.284 & 0.161 & 0.407 \\
\hline Yunnan & 0.526 & 0.448 & 0.603 \\
\hline Shaanxi & 0.182 & 0.095 & 0.268 \\
\hline Gansu & 0.456 & 0.447 & 0.465 \\
\hline Ningxia & 0.886 & 0.772 & 1.000 \\
\hline Eastern region & 0.742 & 0.648 & 0.836 \\
\hline Middle region & 0.358 & 0.320 & 0.396 \\
\hline Western region & 0.535 & 0.482 & 0.589 \\
\hline Overall & 0.566 & 0.501 & 0.631 \\
\hline
\end{tabular}




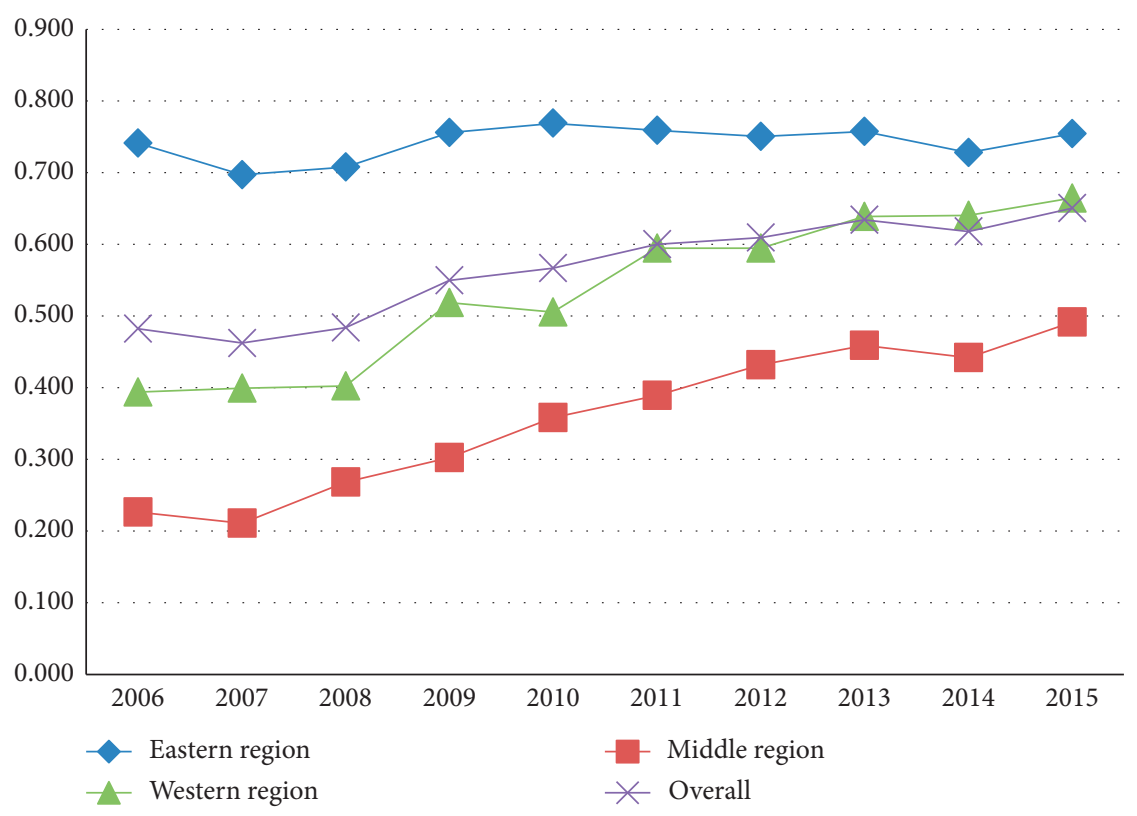

FiguRE 5: Regional differences in conventional innovation efficiency in China's high-tech manufacturing industry without considering environmental pollution.

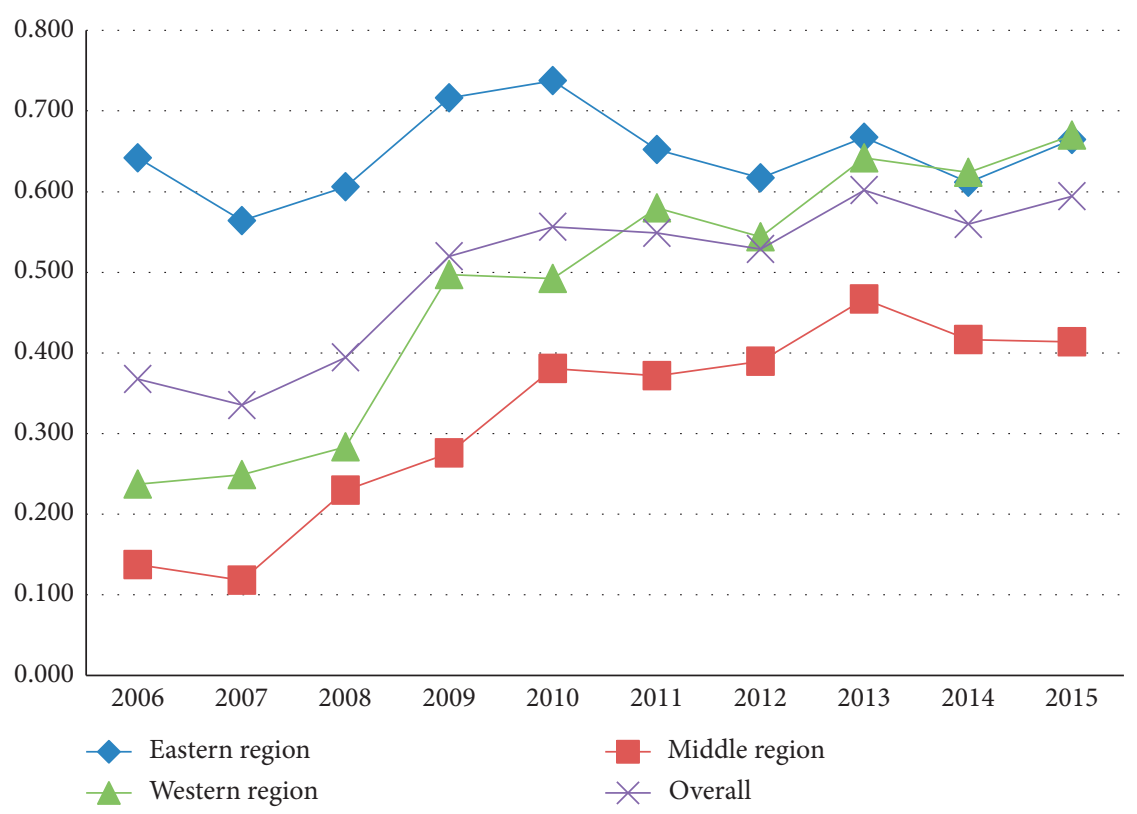

Figure 6: Regional differences in R\&D efficiency in China's high-tech manufacturing industry without considering environmental pollution.

to 2009 , followed by an "S"-shaped growing trend between 2010 and 2015. In general, when not taking environmental pollution into account, R\&D efficiency in China's high-tech manufacturing industry also exhibits a growing trend.

As can be known from Table 3, when not taking environmental pollution into account, Beijing, Shanghai, Jiangsu, Guangdong, and Ningxia are effective in the achievement transformation stage in the high-tech manufacturing industry, while other provinces are ineffective. Among the ineffective provinces, Inner Mongolia, Tianjin, and Hainan have a relatively higher achievement transformation efficiency in their high-tech manufacturing industries, with annual mean values being $0.995,0.991$, and 0.969 , respectively. The province having the lowest achievement transformation efficiency in China's high-tech manufacturing industry is Shaanxi, with an annual mean value of only 0.268 . In addition, Shanxi, Heilongjiang, and Jiangxi also showed relatively lower achievement transformation efficiencies in their high-tech manufacturing industries, with annual mean values being $0.280,0.301$, and 0.334 , respectively. Figure 7 presents regional differences in terms of achievement transformation efficiencies in China's 


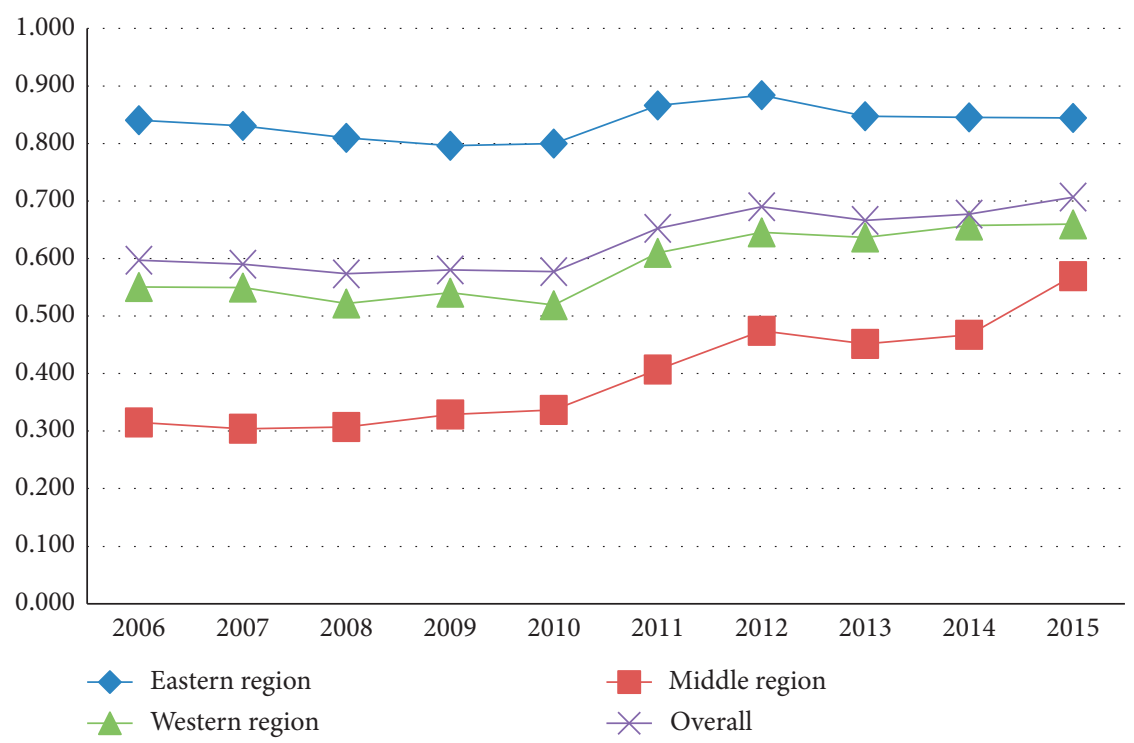

FIgURE 7: Regional differences in achievement transformation efficiency in China's high-tech manufacturing industry without considering environmental pollution.

high-tech manufacturing industry without considering environmental pollution.

When not taking environmental pollution into account, the eastern region's achievement transformation efficiency in the high-tech manufacturing industry is far higher than those of the central and western regions from 2006 to 2015. The eastern region's achievement transformation efficiency in the high-tech manufacturing industry experienced a "downward-upward-downward" process, with the efficiency constantly fluctuating within the range of [0.796, 0.884]. In the central region, achievement transformation efficiency in the high-tech manufacturing industry declined slowly from 2006 to 2007 and then exhibited a growing trend between 2008 and 2015. In the western region, achievement transformation efficiency in the high-tech manufacturing industry exhibited a declining trend from 2006 to 2010, followed by a growing trend from 2011 to 2015. In general, when not taking environmental pollution into account, achievement transformation efficiency in China's high-tech manufacturing industry exhibited an "S"-shaped downward trend first and then an " $S$ "-shaped upward trend.

4.3. Comparison of Estimation Results between Green Innovation Efficiency and Conventional Innovation Efficiency. From 2006 to 2015, both the green innovation efficiency and conventional innovation efficiency of China's high-tech manufacturing industry were considerably low (which were 0.600 and 0.566 , respectively). From the IVC perspective, it can be attributed to the phenomenon where the majority of provinces simultaneously have low efficiencies during the R\&D stage and achievement transformation stage (when taking environmental pollution into consideration, the mean values of R\&D efficiency and achievement transformation efficiency are 0.514 and 0.685 ; when not taking environmental pollution into account, the mean values are 0.501 and 0.631), and the inefficient phenomenon is especially salient during the R\&D stage. Both the green innovation efficiency and conventional innovation efficiency in China's high-tech manufacturing industry have significant regional differences, which are higher in the eastern region than in the central and western regions. During the $\mathrm{R} \& \mathrm{D}$ stage, such regional differences are more salient.

When taking environmental pollution into consideration, green innovation efficiency in China's high-tech manufacturing industry started to decline after 2009, followed by a slow growth; provincially, Beijing, Shanghai, Inner Mongolia, and Hainan have a green innovation efficiency of 1.000 in their high-tech manufacturing industries. When not taking environmental pollution into account, conventional innovation efficiency in China's high-tech manufacturing industry still exhibited a growing trend in 2009; provincially, only Beijing and Shanghai reached a 1.000 conventional innovation efficiency in their high-tech manufacturing industries.

\section{Discussion}

5.1. Theoretical Implications. Few existing studies focusing on innovation efficiency in China's high-tech manufacturing industry have considered environmental pollution, and the findings of these studies often highlight the economic benefits of innovation but ignored its environmental benefits. Luo et al. [32] proposed the innovation value chain model for China's high-tech manufacturing industry but failed to consider the environmental pollution. Luo et al. [33] proposed the green innovation value chain model for the industrial sector without considering supplementary inputs. In this paper, environmental pollution and supplementary inputs are both incorporated into the analytical framework for innovation efficiency in the high-tech manufacturing industry, and a conceptual model for green innovation in the high-tech manufacturing industry is established based on the IVC perspective. In addition, green 
innovation efficiency in the high-tech manufacturing industry is further decomposed into R\&D efficiency and achievement transformation efficiency, deepening the understanding of variations and regional differences in green innovation efficiency in China's high-tech manufacturing industry. Using the network DEA model, this paper also analyzes the differences of estimation results between green innovation efficiency and conventional innovation efficiency, which confirmed that the estimation method for conventional innovation efficiency can produce bias, thereby providing a reference for improving estimation methods for innovation efficiency.

5.2. Practical Implications. This research shows that both the green innovation efficiency and conventional innovation efficiency in China's high-tech manufacturing industry are relatively low. Despite substantial technological advancement in areas of manned space programs and the BeiDou Navigation Satellite System, the overall level of China's research and development is still considerably low and China relies heavily on foreign countries in terms of core technologies, as manifested by chip importation. On the one hand, China's inputs in basic research and R\&D programs with original innovations are lower than international levels. On the other hand, China's high-tech manufacturing industry is less concentrated, as manifested by a large number of small-sized manufacturing firms with no proprietary core technologies and limited R\&D inputs that are distributed to numerous firms, leading to a severe shortage of R\&D inputs for original innovations. Regionally, the eastern region in China enjoys more abundance technological resources and has a relatively sophisticated mechanism to transform technological achievements in comparison with the central and western regions. As such, the eastern region produces higher technological outputs and economic benefits.

With in-depth implementation of the Circular Economy Promotion Law of the People's Republic of China, more stringent requirements pertaining to pollutant discharges will be imposed on manufacturing firms in China. To meet environmental regulations, part of the high-tech manufacturing firms may adopt measures like production cut and technological reformation in order to satisfy the requirement of emission reduction. Although environmental regulation may have caused reduced economic outputs from the high-tech manufacturing industry in the short term, in the long run, there has been no sign of declined innovation outputs from the high-tech manufacturing industry with the implementation of environmental regulations. In addition, Inner Mongolia and Hainan have also gained certain economic and ecological benefits through adjusting industrial structure and protecting the ecological environment, despite their low technological inputs. This also provides a reference for other provinces seeking green innovations in their high-tech manufacturing industries.

5.3. Limitations and Future Research. In this paper, a conceptual framework of green innovation in the high-tech manufacturing industry is constructed based on the IVC perspective; the network DEA model with undesirable outputs is utilized to measure the green innovation efficiency in China's provincial high-tech manufacturing industry from 2006 to 2015, in combination with an in-depth analysis of periodic variations and regional differences. However, due to problems with data availability, this paper fails to consider factors such as energy consumption, soil and water pollution, and the use of chemicals when measuring green innovation efficiency in China's high-tech manufacturing industry. In the meantime, as data on emissions of environmental pollutants by industry was no longer provided by the China Statistical Yearbook on Environment after 2015, this paper also does not estimate green innovation efficiency in China's high-tech manufacturing industry after 2016. In addition, this paper examines the variations in green innovation efficiency in China's high-tech manufacturing industry before and after the implementation of Circular Economy Promotion Law of the People's Republic of China but fails to analyze the relationship between environmental regulation and variations in green innovation efficiency. Subsequent studies will be carried out to establish a theoretical analytical framework aimed at analyzing the effect of environmental regulation on green innovation efficiency in the high-tech manufacturing industry and an econometric model to empirically analyze the relationship between environmental laws and regulations and the variations in green innovation efficiency, thereby providing policy recommendations for improving green innovation efficiency in China's high-tech manufacturing industry.

\section{Conclusions}

In this paper, the green innovation process in the high-tech manufacturing industry is divided into two stages, namely, the $\mathrm{R} \& \mathrm{D}$ stage and the achievement transformation stage, based on the IVC perspective; a network DEA model with undesirable outputs is introduced to measure green innovation efficiency in China's provincial high-tech manufacturing industry; a comparative analysis of estimation results pertaining to the green innovation efficiency and conventional innovation efficiency is carried out. The research shows that, between 2006 and 2015, except for 4 provinces of Beijing, Guangdong, Inner Mongolia, and Hainan, the majority of provinces have ineffective green innovation process in their high-tech manufacturing industries. The annual mean value of green innovation efficiency in China's high-tech manufacturing industry is only 0.600; the green innovation efficiency dropped in 2009 but exhibited an upward trend in general. Regionally, the eastern region has a green innovation efficiency in the high-tech manufacturing industry greater than those of the central and western regions, and regional differences in $\mathrm{R} \& \mathrm{D}$ efficiency are more salient than those in achievement transformation efficiency. From the perspective of innovation value chain, both the R\&D efficiency and achievement transformation efficiency of China's high-tech manufacturing industry are inefficiencies, with the low efficiency phenomenon being more salient in the R\&D stage. Compared with the method of conventional innovation efficiency without considering 
environmental pollution, the estimation method for green innovation efficiency can not only avoid bias of estimation results of provinces producing low pollution emissions like Inner Mongolia and Hainan but also reflect the volatility in efficiency of the high-tech manufacturing industry before and after the implementation of the environmental law.

To improve green innovation efficiency in China's hightech manufacturing industry, efforts should be first concentrated on improving the R\&D efficiency. Regional distribution of technological resources should be optimized to promote coordinated development in terms of technological resources across the eastern, central, and western regions. Oriented towards market demands, active guidance should be provided to steer the capital factor towards the R\&D area and support high-tech manufacturing firms to conduct $R \& D$ activities. Second, equal importance should also be attached to improving the achievement transformation efficiency. The mechanism of technological achievement transformation should be perfected and construction of intermediary service institutions and intermediate platforms should be advanced in order to provide high-precision services for achievement transformation. Communications associating with technological achievement transformation between the eastern, central, and western regions should be pushed forward, and resource distribution pertaining to regional achievement transformation should be optimized through measures like industry-university collaboration and technology transfer. Finally, the high-tech manufacturing industry should pay equal attention to economic and environmental benefits while carrying out innovation processes to avoid sacrificing environmental benefits in exchange for short-term economic gains. Although environmental regulations may result in a short-term reduction in economic outputs, in the long run, environmental regulations will promote highquality development of the high-tech manufacturing industry. Local governments should further improve their assessment systems over the circular economy and urge high-tech manufacturing firms to adopt clean technologies to reduce pollutant discharges and thereby achieve coordinated development between technology, economy, and ecology.

\section{Data Availability}

The data of this study are obtained from China Statistics Yearbook on High Technology Industry, China Industry Statistics Yearbook, and China Statistical Yearbook on Environment. The data can be downloaded from the website of National Bureau of Statistics.

\section{Conflicts of Interest}

The authors declare that there are no conflicts of interest regarding the publication of this paper.

\section{Acknowledgments}

This study was supported by the Project of Humanities and Social Sciences of Ministry of Education of China
(18YJC630131) and the Project of Humanities and Social Sciences Key Research Base of Ministry of Education of China (17JJD790012).

\section{References}

[1] Y. L. Yao, "Spatial overlap of regional innovation capability and high-tech industry," International Journal of Technology Management, vol. 28, no. 3-6, pp. 615-632, 2004.

[2] H. Chen, J. Hou, and W. Chen, "Threshold effect of knowledge accumulation between innovation path and innovation performance: new evidence from China's high-tech industry," Science, Technology and Society, vol. 23, no. 1, pp. 163-184, 2018.

[3] X. Zhang and C. Liu, "Research on innovation knowledge spillover effect of China's high-tech industry R\&D-Base on multidimensional spatial weight matrices," Journal of Advanced Computational Intelligence and Intelligent Informatics, vol. 22, no. 4, pp. 437-447, 2018.

[4] G. C. S. Lin and C. Wang, "Technological innovation in China's high-tech sector: insights from a 2008 survey of the integrated circuit design industry in Shanghai," Eurasian Geography and Economics, vol. 50, no. 4, pp. 402-424, 2009.

[5] J. Hong, B. Feng, Y. Wu, and L. Wang, "Do government grants promote innovation efficiency in China's high-tech industries?" Technovation, vol. 57-58, pp. 4-13, 2016.

[6] S. Cao, F. Feng, W. Chen, and C. Zhou, "Does market competition promote innovation efficiency in China's hightech industries?" Technology Analysis \& Strategic Management, vol. 32, no. 4, pp. 429-442, 2020.

[7] Q. Li and T. Liu, "Innovation efficiency of China's high-end manufacturing industry: evidence from super-SBM model and malmquist index," Mathematical Problems in Engineering, vol. 2019, Article ID 632974, 15 pages, 2019.

[8] X. Huang and R. Chi, "Innovation in China's high-tech industries: barriers and their impact on innovation performance," International Journal of Technology Management, vol. 62, no. 1, pp. 35-55, 2013.

[9] C.-H. Wang, C.-H. Chang, and G. C. Shen, "The effect of inbound open innovation on firm performance: evidence from high-tech industry," Technological Forecasting and Social Change, vol. 99, pp. 222-230, 2015.

[10] Q. W. Wang, Y. Hang, L. C. Sun, and Z. Y. Zhao, "Two-stage innovation efficiency of new energy enterprises in China: a non-radial DEA approach," Technological Forecasting and Social Change, vol. 112, pp. 254-261, 2016.

[11] J. Zhu, Y. Wang, and C. Wang, "A comparative study of the effects of different factors on firm technological innovation performance in different high-tech industries," Chinese Management Studies, vol. 13, no. 1, pp. 2-25, 2019.

[12] S. B. Chen, Y. Q. Feng, C. R. Lin, and C. X. Zhang, "Innovation efficiency evaluation of new and high technology industries based on DEA-Malmquist index," Journal of Interdisciplinary Mathematics, vol. 20, no. 6-7, pp. 1497-1500, 2017.

[13] H. Chen, P. He, C. X. Zhang, and Q. Liu, "Efficiency of technological innovation in China's high tech industry based on DEA method," Journal of Interdisciplinary Mathematics, vol. 20, no. 6-7, pp. 1493-1496, 2017.

[14] X. Song and Y. Ding, "Methods for technical innovation efficiency evaluation of high-tech industry with picture fuzzy set," Journal of Intelligent \& Fuzzy Systems, vol. 37, no. 2, pp. 1649-1657, 2019.

[15] X. Liu and T. Buck, "Innovation performance and channels for international technology spillovers: evidence from 
Chinese high-tech industries," Research Policy, vol. 36, no. 3, pp. 355-366, 2007.

[16] K. J. Lv, D. Wang, and Y. Cheng, "Measuring the dynamic performances of innovation production process from the carry-over perspective: an empirical study of China's hightech industry," Transformations in Business \& Economics, vol. 16, no. 3c, pp. 345-361, 2017.

[17] D. Geng, L. Wang, and Z. Yin, "Intelligent analysis on the factors influencing the innovation and development performance of high-tech industry in China, based on two-stages model," Journal of Intelligent \& Fuzzy Systems, vol. 35, no. 3, pp. 2703-2709, 2018.

[18] R. Zhang, B. Sun, and M. Liu, "Do external technology sourcing and industrial agglomeration successfully facilitate an increase in the innovation performance of high-tech industries in China?" IEEE Access, vol. 7, pp. 15414-15423, 2019.

[19] L. Jiang, Y. Jiang, Z. Wu, D. Liao, and R. Xu, "The measurement of innovation efficiency of Chinese high-tech industry using data envelopment analysis," Acta Oeconomica, vol. 65, no. s2, pp. 101-113, 2015.

[20] C. Li, M. Y. Li, L. Zhang et al., "Has the high-tech industry along the belt and road in China achieved green growth with technological innovation efficiency and environmental sustainability?" International Journal of Environmental Research and Public Health, vol. 16, no. 17, Article ID 3117, 2019.

[21] X. Y. Gao, Y. W. Lyu, F. Shi et al., "The impact of financial factor market distortion on green innovation efficiency of high-tech industry," Ekoloji, vol. 28, no. 107, pp. 3449-3461, 2019.

[22] C. Y. Liu, X. Y. Gao, W. L. Ma, and X. T. Chen, "Research on regional differences and influencing factors of green technology innovation efficiency of China's high-tech industry," Journal of Computational and Applied Mathematics, vol. 369, Article ID 112597, 2020.

[23] B. Zhang, Y. Luo, and Y.-H. Chiu, "Efficiency evaluation of China's high-tech industry with a multi-activity network data envelopment analysis approach," Socio-Economic Planning Sciences, vol. 66, pp. 2-9, 2019.

[24] H. Li, H. He, J. Shan, and J. Cai, "Innovation efficiency of semiconductor industry in China: a new framework based on generalized three-stage DEA analysis," Socio-Economic Planning Sciences, vol. 66, pp. 136-148, 2019.

[25] S. Roper, J. Du, and J. H. Love, "Modelling the innovation value chain," Research Policy, vol. 37, no. 6-7, pp. 961-977, 2008.

[26] S. Roper and S. Arvanitis, "From knowledge to added value: a comparative, panel-data analysis of the innovation value chain in Irish and Swiss manufacturing firms," Research Policy, vol. 41, no. 6, pp. 1093-1106, 2012.

[27] M. T. Hansen and J. Birkinshaw, "The innovation value chain," Harvard Business Review, vol. 85, no. 6, pp. 121-142, 2007.

[28] J. Guan and K. Chen, "Measuring the innovation production process: a cross-region empirical study of China's high-tech innovations," Technovation, vol. 30, no. 5-6, pp. 348-358, 2010.

[29] X. Chen, Z. Liu, and Q. Zhu, "Performance evaluation of China's high-tech innovation process: analysis based on the innovation value chain," Technovation, vol. 74-75, pp. 42-53, 2018.

[30] J. L. Du, Y. Liu, and W. X. Diao, "Assessing regional differences in green innovation efficiency of industrial enterprises in China," International Journal of Environmental Research and Public Health, vol. 16, no. 6, Article ID 940, 2019.
[31] Y.-h. Chiu, C.-w. Huang, and Y.-C. Chen, "The R\&D valuechain efficiency measurement for high-tech industries in China," Asia Pacific Journal of Management, vol. 29, no. 4, pp. 989-1006, 2012.

[32] Q. L. Luo, C. L. Miao, L. Y. Sun et al., "Efficiency evaluation of green technology innovation of China's strategic emerging industries: an empirical analysis based on Malmquist-data envelopment analysis index," Journal of Cleaner Production, vol. 238, Article ID 117782, 2019.

[33] T. C. Li, L. Liang, and D. R. Han, "Research on the efficiency of green technology innovation in China's provincial high-end manufacturing industry based on the RAGA-PP-SFA model," Mathematical Problems in EngineeringVol. 2018, Article ID 9463707, 2018.

[34] L. Shao, X. Yu, and C. Feng, "Evaluating the eco-efficiency of China's industrial sectors: a two-stage network data envelopment analysis," Journal of Environmental Management, vol. 247, pp. 551-560, 2019.

[35] A. Charnes, W. W. Cooper, and E. Rhodes, "Measuring the efficiency of decision-making units," European Journal of Operational Research, vol. 3, no. 4, p. 339, 1979.

[36] W. D. Cook and L. M. Seiford, "Data envelopment analysis (DEA) - thirty years on," European Journal of Operational Research, vol. 192, no. 1, pp. 1-17, 2009.

[37] C. Kao, "Network data envelopment analysis: a review," European Journal of Operational Research, vol. 239, no. 1, pp. 1-16, 2014.

[38] P.-C. Chen and S.-W. Hung, "An actor-network perspective on evaluating the R\&D linking efficiency of innovation ecosystems," Technological Forecasting and Social Change, vol. 112, pp. 303-312, 2016.

[39] C. Kao, "Efficiency measurement and frontier projection identification for general two-stage systems in data envelopment analysis," European Journal of Operational Research, vol. 261, no. 2, pp. 679-689, 2017.

[40] R. K. Mavi, R. F. Saen, and M. Goh, "Joint analysis of ecoefficiency and eco-innovation with common weights in twostage network DEA: a big data approach," Technological Forecasting and Social Change, vol. 144, pp. 553-562, 2019.

[41] W. D. Cook, L. Liang, and J. Zhu, "Measuring performance of two-stage network structures by DEA: a review and future perspective," Omega, vol. 38, no. 6, pp. 423-430, 2010.

[42] C. Kao and S.-N. Hwang, "Efficiency decomposition in twostage data envelopment analysis: an application to non-life insurance companies in Taiwan," European Journal of Operational Research, vol. 185, no. 1, pp. 418-429, 2008.

[43] T. R. Sexton and H. F. Lewis, "Two-stage DEA: an application to major league baseball," Journal of Productivity Analysis, vol. 19, no. 2-3, pp. 227-249, 2003.

[44] M. Maghbouli, A. Amirteimoori, and S. Kordrostami, "Twostage network structures with undesirable outputs: a DEA based approach," Measurement, vol. 48, pp. 109-118, 2014.

[45] F. Peng and S. Z. Zhou, "Local technology transfer and innovation efficiency of high-tech industry under environment regulation," Science \& Technology Progress and Policy, vol. 34, no. 22, pp. 115-119, 2017. 